\title{
Does restricted access limit management of invasive urban frogs?
}

\author{
Giovanni Vimercati $\mathbb{D} \cdot$ Sarah J. Davies $\cdot$ Cang Hui $\mathbb{D} \cdot$ John Measey $\mathbb{C}$
}

Received: 1 April 2017 / Accepted: 31 August 2017/Published online: 23 October 2017

(C) Springer International Publishing AG 2017

\begin{abstract}
Management recommendations that target urban invaders should consider environmental and socio-economic aspects peculiar to the urban landscape. Urbanization often leads to the fragmentation of the invaded landscape into subunits inaccessible to managers (restricted access) or for which detailed information is lacking. Using models to explore impact of these limitations on management success provides a useful approach to propose effective countermeasures. Here we deploy a spatially explicit age-structured model applied to a pond network to investigate how restricted access and lack of detailed information may affect management of three invasive anuran species across a peri-urban landscape. The
\end{abstract}

Guest Editors: Mirijam Gaertner, John R.U. Wilson, Marc W. Cadotte, J. Scott MacIvor, Rafael D. Zenni and David M. Richardson/Urban Invasions.

Electronic supplementary material The online version of this article (doi:10.1007/s10530-017-1599-6) contains supplementary material, which is available to authorized users.

G. Vimercati $(\bowtie) \cdot$ S. J. Davies · J. Measey

Centre for Invasion Biology, Department of Botany and

Zoology, Stellenbosch University,

Private Bag X1, Matieland 7602, South Africa

e-mail: gvimercati@outlook.com

S. J. Davies

e-mail: sdavies@sun.ac.za

J. Measey

e-mail: john@measey.com target species, the guttural toad Sclerophrys gutturalis, the African clawed frog Xenopus laevis and the painted reed frog Hyperolius marmoratus, belong to different ecotypes (terrestrial, aquatic and arboreal, respectively) and have different life history traits. We show that restricted property access significantly constrains management success in two of the three species (the guttural toad and the painted reed frog), while lack of detailed information around the invaded landscape impedes successful management in only one species (the guttural toad). The species-dependent response we detected is due to contrasting demographic and spatial invasion dynamics linked to the different anuran ecotypes. Our work highlights the necessity to adopt a context-dependent approach when proposing management recommendations in urban environment.

Keywords Age-structured model $\cdot$ Amphibian ecotypes $\cdot$ Context-dependent approach $\cdot$ Information

\footnotetext{
C. Hui

Centre for Invasion Biology, Department of Mathematical

Sciences, Stellenbosch University,

Private Bag X1, Matieland 7602, South Africa

e-mail: chui@sun.ac.za

C. Hui

Mathematical and Physical Biosciences, African Institute for Mathematical Sciences, Cape Town 7945, South Africa
} 
incompleteness $\cdot$ Landscape fragmentation $\cdot$ Social dimension

\section{Introduction}

Negative impacts of biological invasions on human health and natural and economic systems have been comprehensively documented (Olson 2006; Pyšek and Richardson 2010; Simberloff et al. 2013; Hulme 2014; Tittensor et al. 2014). Such impacts are often amplified in urban areas (Gaertner et al. 2016), not only because cities are characterized by high-density populations but also due to the unceasing movement of people and commodities through intra- and inter-urban transport linkages, boosting pressure of invasive propagules (Lockwood et al. 2005; Dehnen-Schmutz et al. 2007). Urban invaders can alter ecosystem services (van Wilgen and Scott 2001; Vilà et al. 2009), threaten human health (Juliano and Lounibos 2005; Kohli et al. 2006) and disrupt landscape aesthetics (Fuller et al. 2007). It follows that a considerable amount of management effort is required in an urban context to limit spread of invasive taxa and to minimize their effects once established. Although many interacting factors can contribute to successfully managing urban invaders, it is crucial to consider the temporal scale and the implementation plan of management efforts (Simberloff 2003; Finnoff et al. 2005; Mehta et al. 2007). This requires the consideration of environmental and socio-economic aspects linked to the invaded landscape, as well as the biology and autecology of the invasive species (Coutts et al. 2011; Steel et al. 2014).

Management of invaders may be particularly problematic when the landscape has been fragmented into many subunits such as in urban areas, and more generally in human modified landscapes. The high number of agents (i.e. autonomous entities capable of taking decisions and interacting with the environment and other entities: Bousquet and Le Page 2004; Carrasco et al. 2012), may impede the management over the entire landscape and the implementation of coordinated actions. The invaded landscape may be also characterized by conflicts of views and differing interests among stakeholders (Foster and Sandberg 2004; Warren 2007; Novoa et al. 2017), or public opposition to some management practices (Verbrugge et al. 2013; Gaertner et al. 2016). Although these limitations may be tackled through legislation or sustained awareness campaigns (Marchante et al. 2010; Reis et al. 2013), the necessity to rapidly respond to a new invader often makes such efforts ineffective. Evidence shows that underestimating the socio-economic dimension of invasive species management (e.g. differential perceptions or conflicts of interests among stakeholders) may delay our capacity to effectively respond to an invasion (Botham et al. 2009; Mackenzie and Larson 2010) and/or propose realistic management strategies (Gaertner et al. 2016).

In some cases, however, fragmentation that characterizes human modified landscapes may represent an opportunity, rather than a limitation, to control invasive populations. Unsuitable habitat fragments such as highly urbanized sites may constrain dispersal and/or alter behaviour in some species (Joly et al. 2001), thus limiting an invaders' capacity to colonize new fragments and acting as effective barriers to control taxa characterized by localized dispersal (With 2004). Additionally, a subset of fragments could be the target for management, such as those at the invasion front for containing invasive populations from fast spreading (Hui and Richardson 2017). Lastly, dense human populations and increased activities may allow for intense collection of invaluable data to optimize management: examples are high-resolution spatial layers and aerial images on the invaded area (Müllerová et al. 2005), or species occurrence data derived from citizen science (Dickinson et al. 2010).

Invasive populations are by definition characterized by non-equilibrium time-space dynamics (Pyšek and Hulme 2005; Baker and Bode 2016; Hui and Richardson 2017), where an initial lag phase is followed by expansion and dominance phases (Van Wilgen et al. 2014; Epanchin-Niell and Liebhold 2015). A prompt and effective eradication (defined as "the removal of every potentially reproducing individual of a species or the reduction of their population density below sustainable levels", Myers et al. 2000) is therefore optimal in light of a cost-benefit evaluation (Epanchin-Niell et al. 2014) because it can target populations that are still small, both spatially and demographically (lag phase). Conversely, a prolonged and less effective mode of eradication might only slow down an invasive spread, be ineffective in the long term, and raise the costs of future management (Kettenring and Adams 2011). In addition, suboptimal management actions could subtract economic and social resources from those management activities 
such as detection or containment that should be preferentially performed during expansion and dominance phases (Olson and Roy 2005; Mehta et al. 2007; Bogich et al. 2008; Epanchin-Niell et al. 2012; Chadès et al. 2011; Holden et al. 2016). However, the temporal transition between these phases may often be defined only a posteriori (Simberloff 2003), adding uncertainty to the effort of selecting the optimal management strategy (Januchowski-Hartley et al. 2011; Moore et al. 2011; Epanchin-Niell et al. 2014).

Non-equilibrium time-space dynamics are particularly difficult to reconstruct in cases of invasive species characterized by complex life history stages (e.g. aquatic larvae vs. aerial adults, or pelagic larvae vs. sessile adults). Therefore, efforts aiming to make management recommendations should explicitly consider species-specific life history and behavioural traits across the different stages (Shea et al. 2006; Ramula et al. 2008; Morris et al. 2010; Pichancourt et al. 2012; Beaty and Salice 2013). Many anuran amphibians, for example, are characterized by complex life-cycles where an initial aquatic phase (i.e. tadpoles) differs notably from the successive terrestrial phase (i.e. adults) in terms of survival, physiology and selective pressures (Werner and Gilliam 1984; Rowe and Ludwig 1991). As the complexity and interspecific variability of the amphibian life-cycle are unique among tetrapods (Werner and Gilliam 1984), non-linear population dynamics may differ across species and families according to contrasting life history traits (Biek et al. 2002). A recent study aiming to assess negative environmental and socio-economic impacts of invasive amphibians through a generic scoring system, found that the seven most harmful amphibian species across the globe belong to six different families (Measey et al. 2016). As these families notably differ in their habitats and life history traits, it is not clear whether common recommendations can be made for managing invasions of amphibians that belong to different ecotypes (i.e. adapted to specific habitats, Moen et al. 2013; Vidal-García and Keogh 2015). For example, the cane toad Rhinella marina is a large terrestrial anuran that can lay up to 30 000 eggs per clutch and has become invasive in more than 40 countries across the globe (Lever 2001); several different strategies and methods (summarized by Tingley et al. 2017) have been proposed to control or eradicate this species. However, it is not clear to what extent these management recommendations could be successfully applied to invasions of anurans such as the Puerto Rican coqui Eleutherodactylus coqui, an arboreal species that lays between 16 and 41 directly developing eggs and has invaded several Hawaiian Islands (Beard et al. 2009).

Environmental and social features of the invaded area such as fragmentation and restricted access for managers as well as complexity of non-equilibrium time-space dynamics (Pyšek and Hulme 2005) may be effectively integrated through an ecological modelling approach (Caplat et al. 2012; Cuddington et al. 2013; Wood et al. 2015). This allows scientists, managers and policy-makers to formulate predictions concerning efficacy of a specific management program and time required to be successful also incorporating species-specific traits of the invader. Modelling also allows for the exploration of constraints that can hamper program success and propose alternative strategies to withstand or bypass those constraints.

Here we deploy an age-structured model previously designed to reconstruct invasive population dynamics of a toad species in a peri-urban area (i.e. characterized by rural-urban transition landscape) in order to provide management recommendations (Vimercati et al. 2017). Since this peri-urban area is fragmented into private properties with limited access by invasive species managers, it is not clear to what extent a management strategy implemented only on properties accessible by managers may affect invasion dynamics of three anuran species. Firstly, we explore how a scenario incorporating the demographic effects of the current management differs from a no-management (baseline) scenario where the invasive population dynamics are exclusively determined by density dependence dynamics, life history traits and dispersal. Secondly, we evaluate whether a management scenario lacking detailed information on the invaded area (e.g. aerial imagery) but not limited by restricted access, may realise better results than those obtained in the other two scenarios. To address this, we designed a scenario where only properties possessing medium and large ponds (easily identifiable through satellite imagery) but not small ponds (only identifiable through high-definition aerial imagery) can be targeted for eradication. The model forecasts demographic and spatial dynamics of a population of the guttural toad (Sclerophrys gutturalis, a terrestrial pond-breeding amphibian) in response to different removal scenarios and provides management 
recommendations to face restricted access and information incompleteness. To test the generality of this recommendation to different species of amphibians, we also extended the model and the management scenarios to two other pond-breeding anurans which have contrasting life history and dispersal traits, and belong to different ecotypes (aquatic African clawed frogs, Xenopus laevis and arboreal painted reed frogs, Hyperolius marmoratus). We hypothesize that management recommendations valid for one species may have different outcomes when implemented on taxa that differ in terms of habitat preference and life history traits.

\section{Methods}

Choice of example amphibians

The guttural toad Sclerophrys gutturalis, the African clawed frog Xenopus laevis and the painted reed frog Hyperolius marmoratus are the only three invasive species of amphibians in South Africa (all domestic exotics; see Measey et al. 2017) and they are all pondbreeding anurans. The guttural toad has established an alien population in an urban area of Cape Town previously studied to reconstruct invasion dynamics of the species across a pond network (Vimercati et al. 2017). This study generated high-quality data on the invaded landscape (such as spatial distribution of the ponds and landscape structural complexity) that can be used to simulate invasive dynamics of any pondbreeding anuran species. Although the African clawed frog and the painted reed frog do occur in the area (JM $\&$ SD pers. obs.), neither has been monitored, and no management strategy that includes removal has been made. Thus, our scenarios are hypothetical with respect to an invasion by these two species (but see Vimercati et al. 2017 for the guttural toad). These three anurans belong to different super-families (Feng et al. 2017) and possess contrasting life history and dispersal traits (Table 1).

The guttural toad

The guttural toad Sclerophrys gutturalis (Power 1927, Bufonidae: Hyloidea) is a domestic exotic in South Africa (Measey et al. 2017), being native in most of the country but not in Cape Town, where an invasive population was first reported in 2000 (de Villiers 2006). Since then, guttural toads have been observed using artificial ponds for breeding and invade new ponds every year. Although a systematic study around the environmental and economic impacts caused by this invasive population in Cape Town is lacking, the invasion raised concern because of the occurrence in the same area of the IUCN Endangered Western Leopard Toad (Sclerophrys pantherina; Measey et al. 2017). In 2010, the City of Cape Town contracted a private company to perform an extirpation (i.e. eradication at local scale, Panetta 2007) by opportunistically removing toads, mostly adults, from garden ponds, public open spaces and roadways by hand. The removal from the ponds was particularly arduous because toads were all located in private properties not always accessible to the eradicators. The management effort has been prolonged with no interruption until 2016 to both avoid the invasive spread of the population and promote its total extirpation. However, in 2017 the species was still observed to be actively invading this area of Cape Town despite the high number of toads removed across years. To date, it is not clear how management actions performed only on accessible ponds affect the invasive population and whether alternative, more effective, strategies should be implemented. During the extirpation, sex, age class and GPS position of all individuals removed were recorded by the contractors. This information was pivotal to parameterize the agestructured model used by Vimercati et al. (2017, see Appendix A.4) and to compare model predictions around the spatial spread of the invasive population with field observations (see "Discussion" section in the same study). As with most large toad species, the guttural toad is mainly terrestrial and congregates at water features only for breeding and prior to metamorphosis.

\section{The African clawed frog}

The African clawed frog Xenopus laevis (Daudin 1802; Pipidae: Pipoidea) is indigenous to a large region of southern Africa (Furman et al. 2015), but is thought to have displaced a local endemic, Xenopus gilli, within the extreme southwestern Cape, including the City of Cape Town area (Picker and de Villiers 1989). It appears probable that this situation dates back to habitat modifications made by settlers in the 
Table 1 Model parameters used in this study according to the age-structured model described in Vimercati et al. (2017)

\begin{tabular}{|c|c|c|c|c|}
\hline Parameter & Guttural toad & African clawed frog & Painted reed frog & References and notes \\
\hline Clutch size $\left(\phi_{n}\right)$ & $13000^{\mathrm{a}}$ & $1200^{\mathrm{d}}$ & $400^{\mathrm{d}}$ & - \\
\hline $\begin{array}{l}\text { Annual clutch } \\
\text { number }(\mu)\end{array}$ & $2^{\mathrm{a}}$ & $2.33^{\mathrm{d}}$ & $1.25^{\mathrm{d}}$ & - \\
\hline Adult sex ratio $(\rho)$ & $0.5^{\mathrm{d}}$ & $0.7^{\mathrm{d}}$ & $0.4^{\mathrm{d}}$ & - \\
\hline Probability to lay & $0.06^{\mathrm{a}}$ & $0.05^{\mathrm{d}}$ & $0.2^{\mathrm{d}}$ & - \\
\hline eggs in small, & $0.4^{\mathrm{a}}$ & $0.5^{\mathrm{d}}$ & $0.6^{\mathrm{d}}$ & - \\
\hline $\begin{array}{l}\text { medium and large } \\
\text { ponds respectively } \\
\left(\overline{\mathrm{e}}_{\mathrm{s}, \mathrm{m}, \mathrm{l}}\right)\end{array}$ & $0.22^{\mathrm{a}}$ & $0.25^{\mathrm{d}}$ & $0.4^{\mathrm{d}}$ & - \\
\hline Egg survival $\left(\sigma_{\mathrm{e}}\right)$ & $0.7^{\mathrm{c}}$ & $0.5^{\mathrm{d}}$ & $0.5^{\mathrm{d}}$ & $\begin{array}{l}\text { Blaustein et al. (1994), Biek et al. } \\
\text { (2002) }\end{array}$ \\
\hline $\begin{array}{l}\text { Maximum larval } \\
\text { survival }\left(\sigma_{\text {tmax }}\right)\end{array}$ & $0.8^{\mathrm{c}}$ & $0.5^{\mathrm{d}}$ & $0.5^{\mathrm{d}}$ & Vonesh and De la Cruz (2002) \\
\hline $\begin{array}{l}\text { Density-dependent } \\
\text { coeff. (d) }\end{array}$ & $0.007^{\mathrm{c}}$ & $0.04^{\mathrm{d}}$ & $0.07^{\mathrm{d}}$ & Vonesh and De la Cruz (2002) \\
\hline $\begin{array}{l}\text { Annual proportion of } \\
\text { competing tadpoles } \\
\text { from the same } \\
\text { female (c) }\end{array}$ & $0.5^{\mathrm{a}}$ & $0.5^{\mathrm{d}}$ & $0.5^{\mathrm{d}}$ & - \\
\hline $\begin{array}{l}\text { Pond area of small, } \\
\text { medium and large } \\
\text { ponds respectively } \\
\left(\mathrm{A}_{\mathrm{s}, \mathrm{m}, \mathrm{l}}\right)\end{array}$ & $\begin{array}{l}2.5 \mathrm{~m}^{2 \mathrm{a}} \\
25 \mathrm{~m}^{2 \mathrm{a}} \\
250 \mathrm{~m}^{2}\end{array}$ & $\begin{array}{l}2.5 \mathrm{~m}^{2 \mathrm{a}} \\
25 \mathrm{~m}^{2 \mathrm{a}} \\
250 \mathrm{~m}^{2 \mathrm{a}}\end{array}$ & $\begin{array}{l}2.5 \mathrm{~m}^{2 \mathrm{a}} \\
25 \mathrm{~m}^{2 \mathrm{a}} \\
250 \mathrm{~m}^{2 \mathrm{a}}\end{array}$ & $\begin{array}{l}\text { Estimated in the CT invaded area } \\
\text { through aerial imaging and } \\
\text { reported in Vimercati et al. } \\
(2017)\end{array}$ \\
\hline $\begin{array}{l}\text { Density-dependent } \\
\text { exponent }(\gamma)\end{array}$ & $1^{\mathrm{c}}$ & $1^{\mathrm{d}}$ & $1^{\mathrm{d}}$ & $\begin{array}{l}\text { Vonesh and De la Cruz (2002), } \\
\text { Vimercati et al. (2017) }\end{array}$ \\
\hline $\begin{array}{l}\text { Pond-edge area } \\
\text { within a radius of } 5 \\
\text { meters }\left(\mathrm{E}_{\mathrm{s}, \mathrm{m}, \mathrm{l}}\right)\end{array}$ & $\begin{array}{l}106.4 \mathrm{~m}^{2 \mathrm{a}} \\
166 \mathrm{~m}^{2 \mathrm{a}} \\
357.7 \mathrm{~m}^{2 \mathrm{a}}\end{array}$ & $\begin{array}{l}\text { Density-dependence } \\
\text { survival of } \\
\text { metamorphs linked to } \\
\text { the pond-edge is not } \\
\text { implemented }\end{array}$ & $\begin{array}{l}\text { Density-dependence } \\
\text { survival of } \\
\text { metamorphs linked } \\
\text { to the pond-edge is } \\
\text { not implemented }\end{array}$ & $\begin{array}{l}\text { Calculated using the pond area } \\
A_{\mathrm{s}, \mathrm{m}, \mathrm{l}} \text {, as reported in Vimercati } \\
\text { et al. }(2017)\end{array}$ \\
\hline Juvenile survival $\left(\sigma_{\mathrm{j}}\right)$ & $0.2^{\mathrm{c}}$ & $0.4^{\mathrm{d}}$ & $0.3^{\mathrm{d}}$ & $\begin{array}{l}\text { Lampo and De Leo (1998), } \\
\text { Vonesh and De la Cruz (2002), } \\
\text { Biek et al. (2002) }\end{array}$ \\
\hline $\begin{array}{l}\text { Maturing probability } \\
\text { (P) }\end{array}$ & $0.25^{\mathrm{c}}$ & $0.25^{\mathrm{d}}$ & $0.25^{\mathrm{d}}$ & Vonesh and De la Cruz (2002) \\
\hline Adult survival $\left(\sigma_{\mathrm{a}}\right)$ & $0.6^{\mathrm{c}}$ & $0.4^{\mathrm{d}}$ & $0.5^{\mathrm{d}}$ & $\begin{array}{l}\text { Vonesh and De la Cruz (2002), } \\
\text { Biek et al. (2002) }\end{array}$ \\
\hline $\begin{array}{l}\text { Juvenile probability } \\
\text { to show philopatry } \\
\text { (phi) }\end{array}$ & $0.66^{\mathrm{d}}$ & $0.75^{\mathrm{d}}$ & $0.85^{\mathrm{d}}$ & - \\
\hline $\begin{array}{l}\text { Adult probability to } \\
\text { show site fidelity } \\
\text { (fid) }\end{array}$ & $0.8^{\mathrm{d}}$ & $0.95^{\mathrm{d}}$ & $0.75^{\mathrm{d}}$ & - \\
\hline $\begin{array}{l}\text { Cost configuration to } \\
\text { calculate least-cost } \\
\text { path through } \\
\text { landscape } \\
\text { resistance approach }\end{array}$ & $\begin{array}{l}\text { Grass }=2^{\mathrm{d}} \\
\text { Wall }=8^{\mathrm{d}} \\
\text { Street }=1^{\mathrm{d}} \\
\text { Streams and } \\
\quad \text { rivers }=2^{\mathrm{d}}\end{array}$ & $\begin{array}{l}\text { Grass }=3^{\mathrm{d}} \\
\text { Wall }=8^{\mathrm{d}} \\
\text { Street }=5^{\mathrm{d}} \\
\text { Streams and } \\
\quad \text { rivers }=1^{\mathrm{d}}\end{array}$ & $\begin{array}{l}\text { Grass }=3^{\mathrm{d}} \\
\text { Wall }=1^{\mathrm{d}} \\
\text { Street }=2^{\mathrm{d}} \\
\text { Streams and } \\
\text { rivers }=5^{\mathrm{d}}\end{array}$ & $\begin{array}{l}\text { Costs of locomotion span } \\
\text { between } 1 \text { (lowest cost) and } 8 \\
\text { (highest cost) according to the } \\
\text { ecotype of each species. }\end{array}$ \\
\hline
\end{tabular}


Table 1 continued

\begin{tabular}{|c|c|c|c|c|}
\hline Parameter & Guttural toad & African clawed frog & Painted reed frog & References and notes \\
\hline $\begin{array}{l}\text { Dispersal kernel, } \\
\text { factor norm to } \\
\text { normalize the } \\
\text { kernel }\end{array}$ & $\begin{array}{l}4.1651 \cdot \mathrm{x}^{\wedge(-0.884) \mathrm{c}}, \\
\quad 3.8003^{\mathrm{a}, \mathrm{c}}\end{array}$ & $\begin{array}{l}3.23766 \cdot \mathrm{x}^{\wedge(-0.614981) \mathrm{b}} \\
15.46274^{\mathrm{a}, \mathrm{b}}\end{array}$ & $\begin{array}{l}141.959 \cdot \mathrm{x}^{\wedge(-1.065) \mathrm{c}}, \\
40.73518^{\mathrm{a}, \mathrm{c}}\end{array}$ & $\begin{array}{l}\text { Smith and Green (2006) for the } \\
\text { guttural toad, De Villiers } \\
\text { (2016) for the African clawed } \\
\text { frog, Vos et al. (2000) for the } \\
\text { painted reed frog. }\end{array}$ \\
\hline
\end{tabular}

Symbols represent the different source of information used to define the parameters

${ }^{a}$ Represent species-specific information collected through laboratory and field surveys on the Cape Town population of guttural toad and reported in Vimercati et al. (2017)

${ }^{\mathrm{b}}$ Represent species-specific information collected through a literature review

${ }^{\mathrm{c}}$ Represent information collected from the literature on similar species belonging to the same ecotype

${ }^{\mathrm{d}}$ Represent values assumed to our expert knowledge

early 1600s (Measey et al. 2017). The African clawed frog is invasive on four continents (Measey et al. 2012), with new invasions being reported with increasing frequency around the world (Van Sittert and Measey 2016). It is distinctive among amphibian invasive species as it is principally aquatic, readily moving between aquatic habitats (Measey 2016), but often cryptic as it emits mating calls underwater.

The painted reed frog

The painted reed frog Hyperolius marmoratus (Rapp 1842; Hyperoliidae: Afrobatrachia) is distributed in most of sub-Saharan Africa and in South Africa the historical range extends from the coastal and lowlying areas in the North and East of the country to the central escarpment at about $1600 \mathrm{~m}$ above sea level. (Bishop 2004). At the end of 1990s this species expanded its range from the south-eastern Cape towards the south-west where non-native populations of painted reed frogs were first detected in the central part of the Western Cape (Villiersdorp) in 1997 and in Cape Town, the extreme west of the province in 2004 (Davies et al. 2013). As with many arboreal frogs, this species is particularly resistant to desiccation and principally disperses overland (Withers et al. 1982).

Model construction and management simulations

We used an age-structured model of integrodifference equations to depict the spatial dynamics of invasive frog populations within an urban pond network. The network contains 415 ponds over a $27 \mathrm{~km}^{2}$ peri-urban landscape in Cape Town, South Africa. In the model, each pond hosted a local population of frogs, with individuals exchangeable via distance-limited dispersal. Ponds were located using aerial images and validated through ground truthing. The pond-to-pond connectivity (defined as the probability of an individual from a source pond successfully dispersing into a target pond) was calculated as the distance of the leastcost path using a landscape resistance approach (see below). Population dynamics were captured by traitand density-dependent vital (demographic) rates, with parameter values sourced from the literature, known values of species from the same genus, or expert opinion (see Table 1). Detailed model descriptions are presented in Vimercati et al. (2017).

The model was run for 30 time steps to simulate 30 years of annual population dynamics, from 2001 when the guttural toads were first detected in Cape Town, to 2030. In each step, individuals at different life phases were simulated within-pond life cycle and between-pond dispersal over the entire pond network. Although the three species have different demographic and dispersal traits (Table 1), they share similar life cycles characterized by five life phases: eggs, tadpoles, metamorphs, juveniles and adults. As such, we used the same integrodifference equations reported in Vimercati et al. (2017), except for the density-dependent survival during the metamorph phase (Eq. 4 in Vimercati et al. 2017), which was only used for the guttural toad and not for the other two species. Due to the lack of literature on densitydependent survival during the metamorph phase of the African clawed frog and the painted reed frog, we assumed the metamorph survival to be equal to the fixed juvenile survival. 
As the three species belong to different ecotypes (guttural toad $=$ terrestrial, African clawed frog $=$ aquatic, painted reed frog $=$ arboreal), their costs of locomotion differ across urban landscape features. Consequently, we considered species-specific locomotion costs on grass, wall, streets, and streams when calculating the connectivity using the landscape resistance approach (see Vimercati et al. 2017 for details on the approach; Table 1 for species-specific costs). For example, aquatic African clawed frogs have a low locomotion cost for moving along streams but a high cost for moving down a street. In contrast, arboreal painted reed frogs have a low cost for moving over walls (due to their strong climbing ability) and a moderate cost for moving over grass.

In the model, the three species were introduced to the same location (hereafter the initialization pond) and with the same propagule size (40 individuals, see Sect. 2.2.5 in Vimercati et al. 2017). Also, we assumed that in 2011 the number of adult frogs was 700 , for all species, to parameterize their invasion spread within the pond network; this number was estimated for the guttural toad by using eradication data and it has been already used to parameterize a previous version of the model (see Sect. 2.2.7.4 in Vimercati et al. 2017). This allowed us to investigate the invasion dynamics only as a function of contrasting demographic and dispersal traits.

The management strategy of removing only adults was simulated by reducing adult survival by $80 \%$ in target ponds (estimated according to data from the ongoing guttural toad extirpation program in the City of Cape Town; see Vimercati 2017). The removal action was initialized from 2011 in the simulation, when the guttural toad eradication program was first implemented in Cape Town, and interrupted in 2020; this setup enabled us to explore the capacity of a population recovering after the ten-year management period (i.e. 2021-2030).

We simulated different spatial scenarios of selecting targeted ponds for adult frog extirpation. Scenario $\mathrm{S}_{0}$ represented a baseline scenario without removal. Scenario $S_{1}$ simulated adult removal from the ponds currently accessible to the guttural toad management program; this scenario aimed to estimate management constraints imposed by restricted access in the urban landscape. Scenario $S_{2}$ simulated adult removal from ponds classified as medium and large by Vimercati et al. (2017). Because small ponds $\left(\approx 2.5 \mathrm{~m}^{2}\right)$ cannot be detected by satellites but only through aerial imagery, this scenario aimed to estimate the effects of a management strategy lacking highly detailed information of the invaded area but without limits to access private properties. Scenario $S_{3}$ simulated adult removal from all ponds in the area; this scenario aimed to estimate the results of a management strategy based on precise information about the invaded area (in contrast to $S_{2}$ ) and no constraints to access private properties (in contrast to $S_{1}$ ). An additional scenario, $\mathrm{S}_{4}$, simulated $98 \%$ adult removal from all ponds in the area; this percentage was chosen to estimate the time required to crash the invasive populations by a management strategy that removed nearly all adults in the population.

\section{Results}

Invasion dynamics of terrestrial, aquatic and arboreal frogs

The three species exhibited contrasting invasion dynamics when management interventions were not included in the model. The guttural toad (see also Vimercati et al. 2017) showed a classic logistic demographic dynamic (Fig. 1, $\mathrm{S}_{0}$ ) characterized by a lag (2001-2010), an explosion (2011-2013) and a dominance phase (2014-2030) where adult demography at equilibrium was reached in $2016(\mathrm{~N} \approx 3000)$. In 2011, when management started, the population homogenously occupies an area of Cape Town comparable with the area currently targeted for eradication in terms of spatial extent (Fig. 2a). The African clawed frog showed a less coherent pattern (Fig. 1, $\mathrm{S}_{0}$ ) with an extremely short lag phase and two non-consecutive explosion phases (2002-2007; 2015-2021) each followed by a plateau phase (2008-2014; 2022-2030); the second plateau phase led to the adult demography reaching equilibrium $(\mathrm{N} \approx 40000)$. Unlike the guttural toad, in 2011 the African clawed frog population occupied a much smaller spatial extent (Fig. 2). Moreover, in the same year, adults of the African clawed frog were not homogenously distributed across the invaded area, with about half of them occupying only three ponds (Fig. 2d), and one of these ponds had $40 \%$ of the total number of adults $(\approx 700)$, mirroring invasions previously documented (Measey and Tinsley 1998). This 

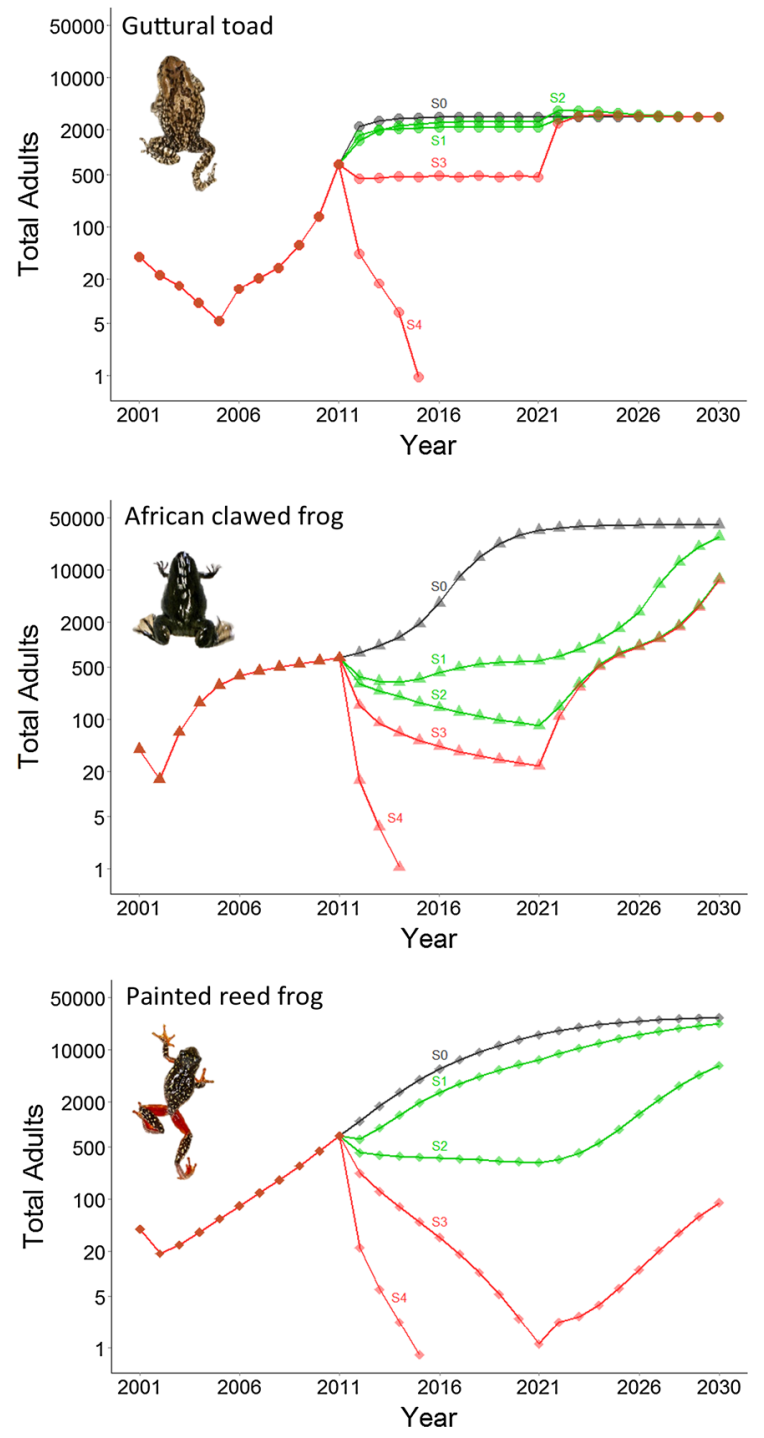

Fig. 1 Adult population size of populations of the guttural toad Sclerophrys gutturalis, the African clawed frog Xenopus laevis and the painted reed frog Hyperolius marmoratus estimated by an age-structured model that simulates the different hypothetical modes of removal listed in Table 2. Colours (green, red and black) indicate how many ponds are targeted for removal (a subset of ponds, all ponds and none of them, respectively). Note the management is simulated to start in 2011 and prolonged for ten years, after which the invasive population is allowed to run for a further ten years until 2030. Note also that the total number of adults in 2011 is $\approx 700$ for all the populations and y-axis is on logarithmic scale

was the same pond we used to initialize the model with 40 adults in 2001. The painted reed frog population showed a very short lag (2001-2003) and accelerating population growth (2004-2016) followed by a slow saturation phase leading to the adult equilibrium
$\left(\mathrm{N} \approx 25000\right.$, Fig. $\left.1 \mathrm{~S}_{0}\right)$. The spatial extent occupied by the painted reed frog in 2011 was very similar to the extent predicted by the model for the guttural toad and approximately similar to the area targeted for eradication. Unlike the guttural toad, adult painted reed frogs were not homogeneously distributed across the ponds, instead most of them invaded the initialization pond $(\approx 20 \%)$ and a few other large ponds nearby. Additionally, in 2011 many small ponds within the invaded area were not occupied by painted reed frogs, especially those ponds close to the invasion front.

How does restricted access constrain management?

Restricting access to properties strongly constrained management of the guttural toads and the painted reed frog in our model, but had a much smaller effect on the removal of the African clawed frog mostly as less ponds were invaded by the time management started. In the guttural toad, the scenario that tested removal from accessible ponds only $\left(\mathrm{S}_{1}\right)$ did not notably differ from the baseline scenario $S_{0}(-25 \%$, Fig. 1) in 2021 (i.e. at the end of management); this mode of removal did not impede the spread of the species across the arena, and non-target ponds acted as stepping stones for the toads to reach the periphery (Fig. 2b, c). Conversely, management extended to all ponds $\left(S_{3}\right)$ had a much higher impact on population demography (-85\%, Fig. 1) although still not sufficient to crash the population. Since the simulated removals started during the demographic explosion, any eradication implemented at this stage of the invasion should be ineffective to extirpate a guttural toad population (unless almost all adults are removed, see $\mathrm{S}_{4}$ ). The constraining role played by restricted access to ponds by eradicators is confirmed in the painted reed frog simulations; although in 2021 the scenario $\mathrm{S}_{1}$ noticeably differed from the baseline scenario $(-55 \%$, Fig. 1), a removal implemented on all ponds $\left(\mathrm{S}_{3}\right)$ almost crashed the population in $2021(-99.9 \%$, Fig. 1). Like observations for the guttural toad, the ponds not targeted for eradication allowed painted reed frogs to invade the periphery of the study area. Conversely, management of the African clawed frog was much less constrained by restricted access; removal from only accessible ponds resulted in reduction of the adult population by $98 \%$ in 2021 (Figs. 1, 2e) and did not significantly differ from 
removal implemented in all ponds $\left(-99.9 \%, \mathrm{~S}_{3}\right.$, Fig. 1). Additionally, this partial removal successfully suppressed the invasion spread of the species across the arena, with only a few ponds still invaded in 2021. Among these, a single non-targeted large pond near the initialization pond was occupied by about $40 \%$ of the African clawed population (Fig. 2e, supplementary material). In 2011, the spatial extent of the African clawed frog population was much lower than the area targeted for eradication with only few ponds invaded (Fig. 2d); additionally, the demography of the population showed a plateau phase (Fig. 1). These peculiar spatial and demographic aspects could facilitate successful management of the species despite some properties were not accessible by managers. However, neither mode of removal $\left(S_{1}, S_{3}\right)$ was sufficient to fully extirpate the population in the next ten years (Fig. 2f).

How does lack of detailed information on the invaded area hamper management?

Lack of detailed information on the invaded area strongly hampered management in the guttural toad, but this was not the case for the African clawed frog or the painted reed frog. In the guttural toad, a mode of removal that targets only medium and large ponds $\left(\mathrm{S}_{2}\right)$ did not have any noticeable impact on population demography ( $-15 \%$ in 2021, Fig. 1). Conversely this mode of removal severely affected demography in the African clawed frog $(-99.7 \%)$ and in the painted reed frog $(-98 \%)$ although it was not sufficient to crash either population. In these two species, removal from large and medium ponds was also more effective than removal implemented in all accessible ponds. This can be partially attributed to the different number of ponds targeted for eradication in the two scenarios $\left(S_{2}>S_{1}\right.$; Table 2). However, the tendency we detected for African clawed frogs and painted reed frogs to invade a few large ponds (Fig. 2d, g) instead of being homogenously widespread across the invaded area (Fig. 2a) may facilitate this removal if these ponds can be identified early on.

\section{Discussion}

Here we show how the social dimension of an urban area strongly impedes management of invasive terrestrial frogs (i.e. the guttural toad) and can theoretically limit management of arboreal frogs (i.e. the painted reed frog) through restricting pond access by eradicators. Conversely, the same restricted access does not significantly affect a hypothetical management of aquatic frogs (i.e. the African clawed frog). We also show that in the guttural toad invasion, detection of ponds using aerial imagery is necessary to ensure that the control operations were successful. However, any removal performed during the toads' demographic explosion fails to crash the invasive population (with the exception of the removal of almost all adults). Management recommendations for invasive populations of guttural toads require tackling social limitations, using detailed information on the invaded landscape and acting before the occurrence of a demographic explosion phase. However, we also find that these recommendations may not necessarily be useful to manage frogs belonging to different ecotypes; indeed, contrasting demographic and dispersal traits lead to divergent invasion dynamics and this should be recognized in management planning: one plan does not fit all invasive frogs.

The main obstacle to the successful extirpation of toads comes from spatial limitations linked to the social dimension of the landscape. The complex periurban landscape did not allow monitoring of the invaded area as a whole, because it was fragmented into around 3000 private properties (Vimercati et al. 2017). Given that only two to three properties could be visited per night by the eradicators (G.V. pers. obs.), it was not possible to remove invasive individuals from the whole area. Our simulations showed however that the number of ponds accessible for management was insufficient to limit the spread of guttural toads across the area and only reduced the density of toads (Fig. 2b, supplementary material). Inaccessible ponds are utilized by the toads as invasion hubs at a small scale to spread across the area (Florance et al. 2011) making the eradication ineffective. Only a minority (about $15 \%$ ) of the ponds mapped through aerial imaging (see Vimercati et al. 2017) were not targeted for removal because they were totally unknown to the eradicators.

Toad presence was locally confirmed by hearing the breeding call for most of the mapped ponds, but the eradicators failed to obtain access from the owners of some private properties containing ponds. For example, some owners were pleased to have frogs in their gardens and disagreed with the removal campaign, 


\section{Guttural toad}

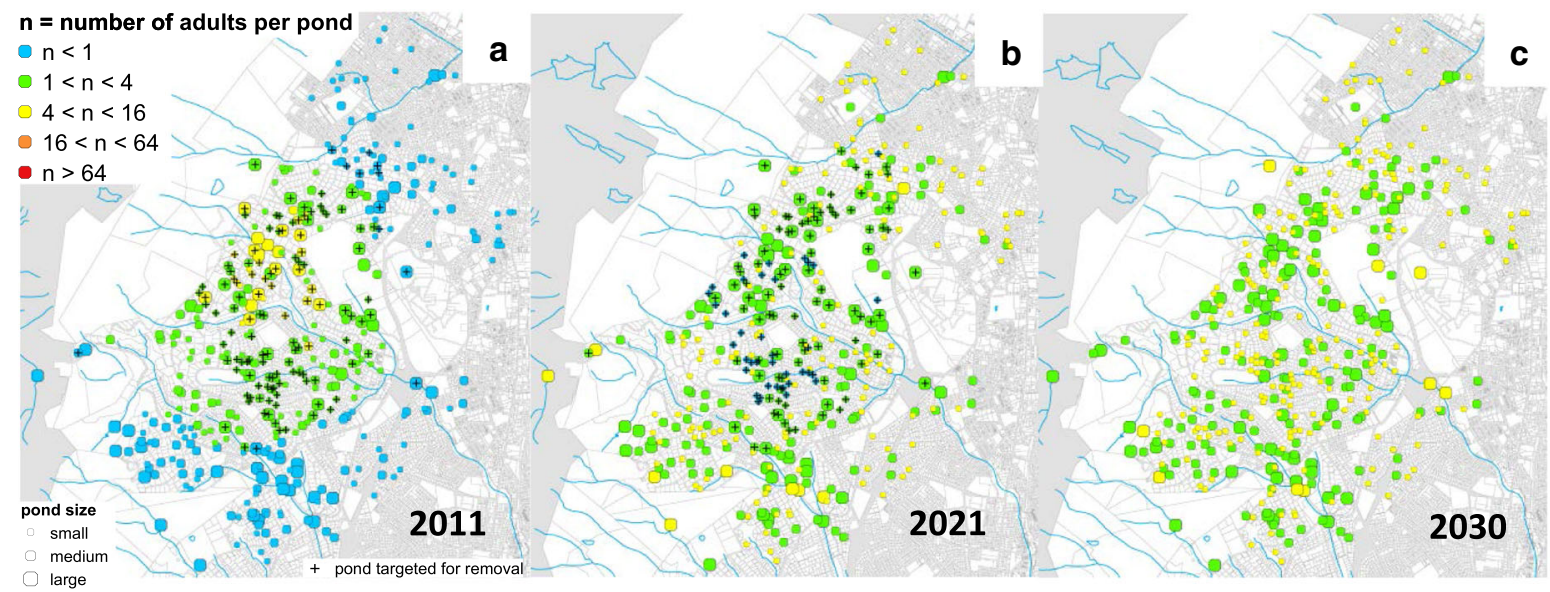

\section{African clawed frog}

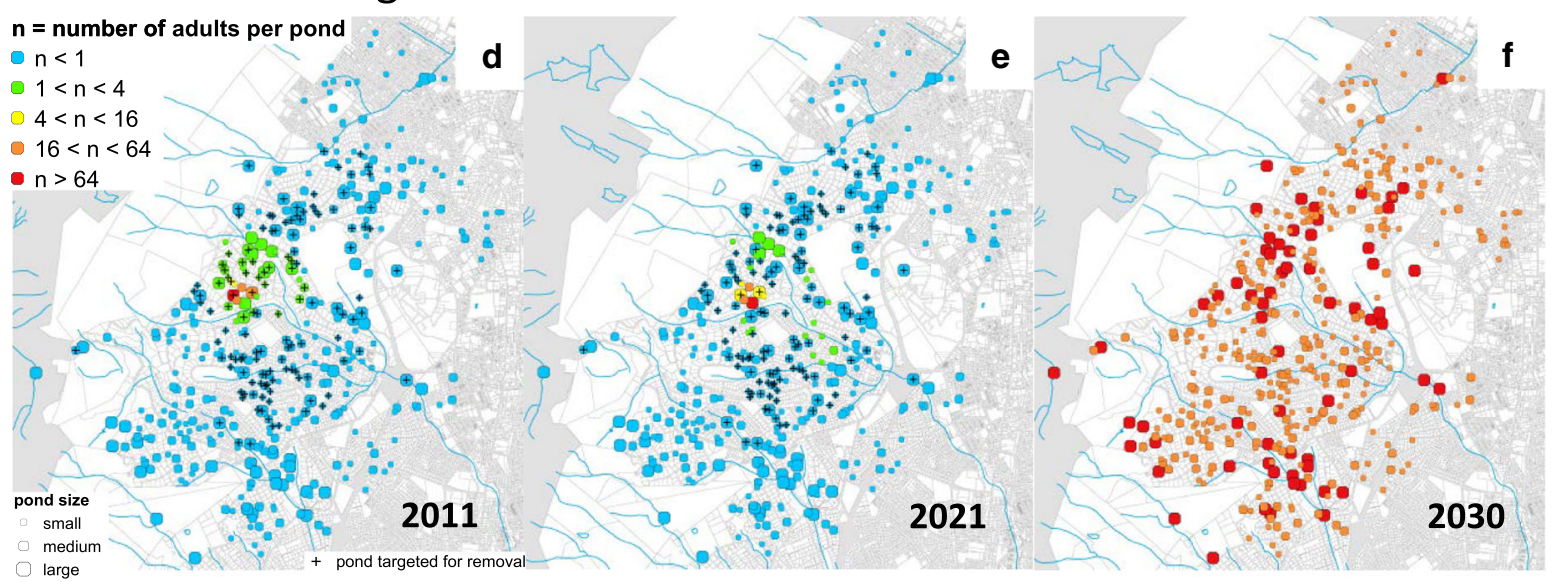

\section{Painted reed frog}

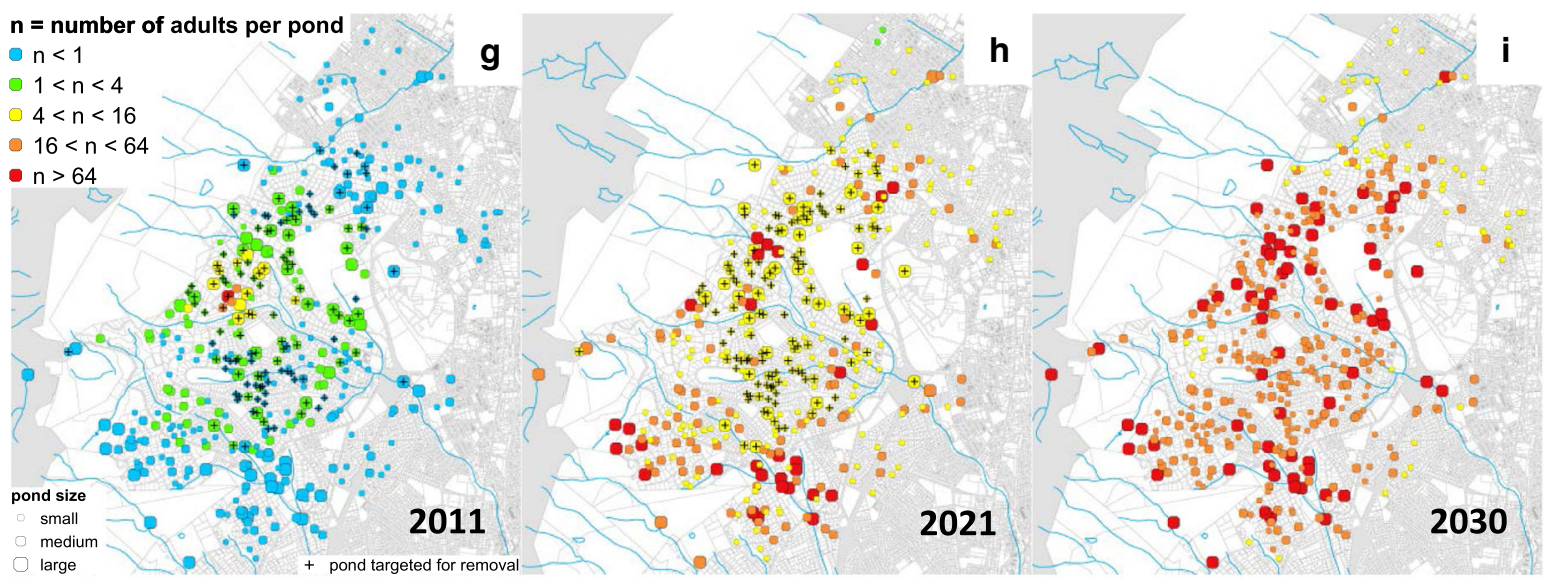


4Fig. 2 Spatial layers showing the spatial dynamics of the guttural toad Sclerophrys gutturalis $(\mathbf{a}-\mathbf{c})$, the African clawed frog Xenopus laevis $(\mathbf{d}-\mathbf{f})$ and the painted reed frog Hyperolius marmoratus (g-i) across years as estimated by an age-structured model that simulates the scenario $\mathrm{S}_{1}$ (Table 2). Colours represent different number of individuals predicted by the model where crosses represent accessible ponds targeted for removal. Note the management is simulated to start in 2011 and prolonged for ten years after which the invasive population is allowed to run for a further ten years until 2030 . Note also that the total number of adults in 2011 is $\approx 700$ for all the populations. The spatial and demographic data used to show the invasion dynamics of the three species in the scenario $S_{1}$ are reported in the supplementary material

while others simply did not reply to phone calls or printed information about the toad removal program. As legislation at the time did not provide for compulsory access, removal from many properties was not possible. In 2015 the guttural toad was listed under Chapter 5 of the National Environmental Management: Biodiversity Act (NEM:BA, 2004) and recognized as an invasive species that must be controlled (Category 1b, Measey et al. 2017). Effective invasive species regulations earlier in the process (e.g. in 2011), would have promoted more effective management operations, although the high number of agents involved in management would likely continue to impede effective control actions across the entire area (Bousquet and Le Page 2004; Carrasco et al. 2012).

The invasion dynamics of African clawed frogs are characterized by much slower spread across the periurban landscape where a few ponds are occupied,

Table 2 Proportions of guttural toads Sclerophrys gutturalis, African clawed frogs Xenopus laevis and painted reed frogs Hyperolius marmoratus removed from each pond in simulated removal scenarios using an age-structured model. $\mathrm{S}_{0}$ represents resulting in a very high density of individuals in those ponds (Fig. 2d). The dispersal abilities of the African clawed frog are lower than those of the other two taxa (see dispersal kernel in Table 1); therefore, these frogs slowly became abundant in ponds where the access for managers could theoretically be obtained from the owners of the properties. In our model, this allowed for more successful management. Although in the study area restricted access may not represent a severe limitation to the control of the African clawed frog, this species does not emit calls audible at any distance from a pond (Measey et al. 2012). Therefore, management could still be particularly arduous because of the low species detection probability rather than because of limitations linked to eradication. Known invasive populations of this species in France, Italy and Chile were recognised so late that their invasions are already considered to be beyond eradication (Measey et al. 2012). However, we also argue that in urban environments, a high density of people could help to rapidly detect invasive populations of cryptic species like the African clawed frog by the use of citizen science programs (Silvertown et al. 2015; Davies et al. 2016).

Our study also shows that detailed knowledge of the invasive landscape is necessary not only to predict invasion dynamics but also to plan successful management of toads. However, the same knowledge is much less relevant if we aim to manage the painted reed frog and the African clawed frog. During the demographic explosion of guttural toads, these terrestrial frogs similarly occupy large, medium and small

the baseline scenario without removal; $S_{1-2}$ represent hypothetical scenarios obtained simulating removal from only a specific subset of ponds; $\mathrm{S}_{3-4}$ represent hypothetical scenarios obtained simulating removal from all ponds

\begin{tabular}{|c|c|c|c|}
\hline $\begin{array}{l}\text { Scenarios simulating } \\
\text { different extirpation } \\
\text { strategies }\end{array}$ & $\begin{array}{l}\text { Percentage of adults } \\
\text { removed in each pond }\end{array}$ & $\begin{array}{l}\text { Number of ponds targeted/ } \\
\text { Total number of ponds }\end{array}$ & Rationale \\
\hline$S_{0}$ & 0 & $0 / 415$ & No removal \\
\hline$S_{1}$ & 80 & $128 / 415$ & $\begin{array}{l}\text { Mode that removes by hand and/or by traps } \\
\text { adults only from accessible ponds }\end{array}$ \\
\hline $\mathrm{S}_{2}$ & 80 & $191 / 415$ & $\begin{array}{l}\text { Mode that removes by hand and/or by traps } \\
\text { adults only from medium and large ponds }\end{array}$ \\
\hline $\mathrm{S}_{3}$ & 80 & $415 / 415$ & $\begin{array}{l}\text { Mode that removes by hand and/or by trap } \\
\text { adults from all ponds }\end{array}$ \\
\hline $\mathrm{S}_{4}$ & 98 & $415 / 415$ & $\begin{array}{l}\text { Mode that removes by hand and/or by trap } \\
\text { adults from all ponds }\end{array}$ \\
\hline
\end{tabular}

For each mode of removal, both the number of ponds accessible for eradication and the rationale are reported 
ponds (Fig. 2a) whereas during the dominance phase small ponds are characterized by a higher number of adults than medium and large ponds (Fig. 2c, supplementary material). Although this is counter-intuitive, the dispersal process in our model does not take into account breeding site quality (e.g. preferred dispersal toward larger ponds). Thus, the demographic difference between small and medium/large ponds is only due to pond-related parameters (such as female probabilities to lay eggs, or the ratio between pond area and pond edge area, Table 1) that may have knock-on effects across the life-cycle. This is confirmed by the number of guttural toads in the ponds predicted by the model at different life stages. Small ponds are characterized during the saturation phase by low numbers of eggs, tadpoles and metamorphs (data not reported); however, this situation is reversed in juveniles, suggesting that the metamorph density dependent survival occurring at the pond edge has a much more severe regulatory effect on demography in medium and large ponds. Interestingly, this pattern does not occur during the expansion phase, thus limiting the possibility to perform management by targeting ponds with a specific size during the invasion spread. As a consequence, management of toads should deploy highly detailed information of the invaded landscape in order to identify and manage all ponds present in the invaded area. We suggest that in an urban context, the high number of stakeholders and the disparate activities may allow the collection of an exceptional amount of information (e.g. aerial imagery, GIS layers and citizen scientists) that should be more often used to timely react to certain invasive species.

However, we also observe that, unlike in the guttural toad management, a detailed knowledge of the invaded landscape is much less important to control other frogs like the painted reed frog or the African clawed frog. In our simulations, these frogs tend to be significantly more abundant in large and medium ponds than in small ponds (Fig. $2 d-i$, supplementary material). Given that density-dependent survival at the metamorph- stage of the African clawed frog and the painted reed frog was not implemented in our model (see Methods), pond edge area does not have any regulatory effect on the demography of these two taxa. Therefore, in our model, a management plan implemented on medium and large ponds is sufficient to promote a considerable impact on their invasive populations. Whether this is an artefact generated by our model or a genuine difference between terrestrial and aquatic-arboreal ecotypes demographic dynamics seems ripe for further studies.

Lastly, we showed that not only where (e.g. from accessible ponds) but also when the management is performed plays a crucial role in successful removal or control of invasive species. All the simulated management strategies (with the exception of $\mathrm{S}_{4}$ which removes almost all adults, Fig. 1) failed to crash the population of terrestrial, aquatic and arboreal frogs, i.e. to reach the density threshold that prevents the population from recovering (Simberloff and Gibbons 2004). In addition, only the management strategies simulated on the invasive population of African clawed frogs were able to limit the spread of the species across the area to a smaller subset of ponds. This suggests that in both terrestrial and arboreal frogs, some individuals are always able to reach the most peripheral ponds and continue the invasion (like invasive populations of freshwater snails, Facon and David 2006) despite the removal of a large proportion of the population through control operations. The management was simulated to begin during the demographic explosion of the population in the guttural toad and the painted reed frog. Thus, we argue that an eradication process conducted before this phase could be more effective in crashing the population or at least limit its spread, as suggested here for the African clawed frog invasion and previously by other authors (Pluess et al. 2012; Baker and Bode 2016). Rapid response seems particularly important in species characterized by high dispersal capabilities (Pichancourt et al. 2012; Panetta and Cacho 2014) such as many bufonids and hylids (Smith and Green 2005). If rare long-distance dispersal events enable some individuals to colonize ponds outside the managed area even before the eradication, these individuals could theoretically remain undetected, or non-reproductive, for years before actively contributing to the invasion (Blossey 1999; Hulme 2006; Harvey et al. 2009; Vimercati et al. 2017).

In conclusion, we show that management of anuran urban invaders should take into account the social dimension of the landscape and the level of information we possess on the landscape itself. It is essential that management operations: (1) recognize limitations such as restricted access for managers; (2) adopt, when possible, actions to minimize such limitations; and (3) 
implement effective recommendations, especially at the onset of an invasion. We also show that these recommendations should be preferentially tailored following a context-dependent approach; taxonomically close invasive species characterized by complex life-cycles and differing ecotypes may have very different invasion dynamics and require specific management actions.

Acknowledgements Funding was provided by the DST-NRF Centre of Excellence for Invasion Biology.

\section{References}

Baker C, Bode M (2016) Placing invasive species management in a spatiotemporal context. Ecol Appl 26:712-725. http:// onlinelibrary.wiley.com/doi/10.1890/15-0095/full

Beard KH, Price EA, Pitt W (2009) Biology and Impacts of Pacific Island Invasive Species. 5. Eleutherodactylus coqui, the Coqui Frog (Anura: Leptodactylidae) 1. Pac Sci 63:297-316

Beaty LE, Salice CJ (2013) Size matters: insights from an allometric approach to evaluate control methods for invasive Australian Rhinella marina. Ecol Appl 23:1544-1553. doi:10.1890/12-1298.1

Biek R, Funk WC, Maxell BA, Mills LS (2002) What is missing in amphibian decline research: insights from ecological sensitivity analysis. Conserv Biol 16:728-734

Bishop PJ (2004) Hyperolius marmoratus Rapp, 1842. In: Minter LR, Burger M, Harrison JA, Braack HH, Bishop PJ, Kloepfer D (eds) Atlas and red data book of the frogs of South Africa, Lesotho and Swaziland. Smithsonian Institution, Washington, D.C., pp 141-143

Blaustein AR, Hoffman PD, Hokit DG, Kiesecker JM, Walls SC, Hays JB (1994) UV repair and resistance to solar UV-B in amphibian eggs: a link to population declines? Proc Natl Acad Sci 91:1791-1795

Blossey B (1999) Before, during and after: the need for longterm monitoring in invasive plant species management. Biol Invasions 1:301-311. doi:10.1023/A:1010084724526

Bogich TL, Liebhold AM, Shea K (2008) To sample or eradicate? A cost minimization model for monitoring and managing an invasive species. J Appl Ecol 45:1134-1142. doi:10.1111/j.1365-2664.2008.01494.x

Botham MS, Rothery P, Hulme PE, Hill MO, Preston CD, Roy DB (2009) Do urban areas act as foci for the spread of alien plant species? An assessment of temporal trends in the UK. Divers Distrib 15:338-345. doi:10.1111/j.1472-4642. 2008.00539.x

Bousquet F, Le Page C (2004) Multi-agent simulations and ecosystem management: a review. Ecol modell 176:313-332. doi:10.1016/j.ecolmodel.2004.01.011

Caplat P, Coutts S, Buckley YM (2012) Modeling population dynamics, landscape structure, and management decisions for controlling the spread of invasive plants. Ann NY Acad Sci 1249:72-83. doi:10.1111/j.1749-6632.2011.06313.x
Carrasco LR, Cook D, Baker R, MacLeod A, Knight JD, Mumford JD (2012) Towards the integration of spread and economic impacts of biological invasions in a landscape of learning and imitating agents. Ecol Econ 76:95-103. doi:10.1016/j.ecolecon.2012.02.009

Chadès I, Martin TG, Nicol S, Burgman M, Possingham HP, Buckley YM (2011) General rules for managing and surveying networks of pests, diseases, and endangered species. Proc Natl Acad Sci 108:8323-8328. doi:10.1073/ pnas. 1016846108

Coutts SR, van Klinken RD, Yokomizo H, Buckley YM (2011) What are the key drivers of spread in invasive plants: dispersal, demography or landscape: and how can we use this knowledge to aid management? Biol Invasions 13:1649-1661. doi:10.1007/s10530-010-9922-5

Cuddington K, Fortin MJ, Gerber LR, Hastings A, Liebhold A, O'Connor M, Ray C (2013) Process-based models are required to manage ecological systems in a changing world. Ecosphere 4:1-12. doi:10.1890/ES12-00178.1

Davies SJ, Clusella-Trullas S, Hui C, McGeoch MA (2013) Farm dams facilitate amphibian invasion: extra-limital range expansion of the painted reed frog in South Africa. Austral Ecol 38:851-863

Davies SJ, Measey GJ, Du Plessis D, Richardson DM (2016) Science and education at the Centre for Invasion Biology. In: Castro P, Azeiteiro UM, Bacelar-Nicolau P, Leal Filho W, Azul AM (eds) Biodiversity and education for sustainable development, World Sustainability Series. Springer, Cham, pp 93-105

De Villiers A (2006) Amphibia: anura: Bufonidae Bufo gutturalis Power, 1927 guttural toad introduced population. Afr Herp News 40:28-30

De Villiers FA (2016) The dispersal ability, performance and population dynamics of Cape Xenopus frogs. MSc thesis, Stellenbosch University

Dehnen-Schmutz K, Touza J, Perrings C, Williamson M (2007) A century of the ornamental plant trade and its impact on invasion success. Divers Distrib 13:527-534. doi:10.1111/ j.1472-4642.2007.00359.x

Dickinson JL, Zuckerberg B, Bonter DN (2010) Citizen science as an ecological research tool: challenges and benefits. Annu Rev Ecol Evol Syst 41:149-172

Epanchin-Niell RS, Liebhold AM (2015) Benefits of invasion prevention: effect of time lags, spread rates, and damage persistence. Ecol Econ 116:146-153. doi:10.1016/j. ecolecon.2015.04.014

Epanchin-Niell RS, Haight RG, Berec L, Kean JM, Liebhold AM (2012) Optimal surveillance and eradication of invasive species in heterogeneous landscapes. Ecol Lett 15:803-812. doi:10.1111/j.1461-0248.2012.01800.x

Epanchin-Niell RS, Brockerhoff EG, Kean JM, Turner JA (2014) Designing cost-efficient surveillance for early detection and control of multiple biological invaders. Ecol Appl 24:1258-1274. doi:10.1890/13-1331.1

Facon B, David P (2006) Metapopulation dynamics and biological invasions: a spatially explicit model applied to a freshwater snail. Am Nat 168:769-783. doi:10.1086/ 508669

Feng YJ, Blackburn DC, Liang D, Hillis DM, Wake DB, Cannatella DC, Zhang P (2017) Phylogenomics reveals rapid, simultaneous diversification of three major clades of 
Gondwanan frogs at the Cretaceous-Paleogene boundary. Proc Natl Acad Sci 114:5864-5870. doi:10.1073/pnas. 1704632114

Finnoff D, Shogren JF, Leung B, Lodge D (2005) The importance of bioeconomic feedback in invasive species management. Ecol Econ 52:367-381. doi:10.1016/j.ecolecon. 2004.06.020

Florance D, Webb JK, Dempster T, Kearney MR, Worthing A, Letnic M (2011) Excluding access to invasion hubs can contain the spread of an invasive vertebrate. Proc R Soc Lond Ser B 278:2900-2908. doi:10.1098/rspb.2011.0032

Foster J, Sandberg LA (2004) Friends or foe? Invasive species and public green space in Toronto. Geogr Rev 94:178-198. doi:10.1111/j.1931-0846.2004.tb00166.x

Fuller RA, Irvine KN, Devine-Wright P, Warren PH, Gaston KJ (2007) Psychological benefits of greenspace increase with biodiversity. Biol Lett 3:390-394. doi:10.1098/rsbl.2007. 0149

Furman BL, Bewick AJ, Harrison TL, Greenbaum E, Gvoždík V, Kusamba C, Evans BJ (2015) Pan-African phylogeography of a model organism, the African clawed frog 'Xenopus laevis'. Mol Ecol 24:909-925

Gaertner M, Larson BMH, Irlich UM, Holmes PM, Stafford L, van Wilgen BW, Richardson DM (2016) Managing invasive species in cities: a framework from Cape Town, South Africa? Landsc Urban Plann 151:1-9. doi:10.1016/j. landurbplan.2016.03.010

Harvey CT, Qureshi SA, MacIsaac HJ (2009) Detection of a colonizing, aquatic, non-indigenous species. Divers Distrib 15:429-437

Holden M, Nyrop J, Ellner S (2016) The economic benefit of time-varying surveillance effort for invasive species management. J Appl Ecol 53:712-721. http://onlinelibrary. wiley.com/doi/10.1111/1365-2664.12617/pdf

Hui C, Richardson DM (2017) Invasion dynamics. Oxford University Press, Oxford

Hulme PE (2006) Beyond control: wider implications for the management of biological invasions. J Appl Ecol 43:835-847. doi:10.1111/j.1365-2664.2006.01227.x

Hulme PE (2014) Invasive species challenge the global response to emerging diseases. Trends Parasitol 30:267-270. doi:10. 1016/j.pt.2014.03.005

Januchowski-Hartley SR, Visconti P, Pressey RL (2011) A systematic approach for prioritizing multiple management actions for invasive species. Biol Invasions 13:1241-1253. doi:10.1007/s10530-011-9960-7

Joly P, Miaud C, Lehmann A, Grolet O (2001) Habitat matrix effects on pond occupancy in newts. Conserv Biol 15:239-248

Juliano SA, Lounibos LP (2005) Ecology of invasive mosquitoes: effects on resident species and on human health. Ecol Lett 8:558-574. doi:10.1111/j.1461-0248.2005.00755.x

Kettenring KM, Adams CR (2011) Lessons learned from invasive plant control experiments: a systematic review and meta-analysis. J Appl Ecol 48:970-979. doi:10.1111/j. 1365-2664.2011.01979.x

Kohli RK, Batish DR, Singh HP, Dogra KS (2006) Status, invasiveness and environmental threats of three tropical American invasive weeds (Parthenium hysterophorus L., Ageratum conyzoides L., Lantana camara L.) in India. Biol Invasions 8:1501-1510. doi:10.1007/s10530-005-5842-1
Lampo M, De Leo G (1998) The invasion ecology of the toad Bufo marinus: from South America to Australia. Ecol Appl $8: 388-396$

Lever C (2001) The cane toad: the history and ecology of a successful colonist. Westbury Academic \& Scientific Pub, Otley

Lockwood JL, Cassey P, Blackburn T (2005) The role of propagule pressure in explaining species invasions. Trends Ecol Evol 20:223-228. doi:10.1016/j.tree.2005.02.004

Mackenzie BF, Larson BMH (2010) Participation under time constraints: landowner perceptions of rapid response to the emerald ash borer. Soc Nat Resour 23:1013-1022. doi:10. 1080/08941920903339707

Marchante E, Marchante H, Morais M, Freitas H (2010) Combining methodologies to increase public awareness about invasive alien plants in Portugal. In: 2nd International workshop on invasive plants in the mediterranean type regions of the world. European Environment Agency, Trabzon, pp 227-239

Measey J (2016) Overland movement in African clawed frogs (Xenopus laevis): a systematic systematic review. PeerJ 4:e2474

Measey GJ, Tinsley RC (1998) Feral Xenopus laevis in South Wales. Herpetol J 8:23-27

Measey GJ, Rödder D, Green SL, Kobayashi R, Lillo F, Lobos G, Thirion JM (2012) Ongoing invasions of the African clawed frog, Xenopus laevis: a global review. Biol Invasions 14:2255-2270

Measey GJ, Vimercati G, Villiers FA, Mokhatla M, Davies SJ, Thorp CJ, Kumschick S (2016) A global assessment of alien amphibian impacts in a formal framework. Divers Distrib 22:970-981

Measey J, Davies S, Vimercati G, Rebelo A, Schmidt W, Turner AA (2017) Invasive amphibians in southern Africa: a review of invasion pathways. Bothalia Appl Biodivers Conserv 47:1-12. doi:10.4102/abc.v47i2.2117

Mehta SV, Haight RG, Homans FR, Polasky S, Venette RC (2007) Optimal detection and control strategies for invasive species management. Ecol Econ 61:237-245. doi:10. 1016/j.ecolecon.2006.10.024

Moen DS, Irschick DJ, Wiens JJ (2013) Evolutionary conservatism and convergence both lead to striking similarity in ecology, morphology and performance across continents in frogs. Proc R Soc B 280(1773):20132156

Moore JL, Runge MC, Webber BL, Wilson JRU (2011) Contain or eradicate? Optimizing the management goal for Australian acacia invasions in the face of uncertainty. Divers Distrib 17:1047-1059. doi:10.1111/j.1472-4642.2011. 00809.x

Morris JA, Shertzer KW, Rice JA (2010) A stage-based matrix population model of invasive lionfish with implications for control. Biol Invasions 13:7-12. doi:10.1007/s10530-0109786-8

Müllerová J, Pyšek P, Jarošík V, Pergl JAN (2005) Aerial photographs as a tool for assessing the regional dynamics of the invasive plant species Heracleum mantegazzianum. J Appl Ecol 42:1042-1053

Myers JH, Simberloff D, Kuris AM, Carey JR (2000) Eradication revisited: dealing with exotic species. Trends Ecol Evol 15:316-320. doi:10.1016/S0169-5347(00)01914-5 
Novoa A, Dehnen-Schmutz K, Fried J, Vimercati G (2017) Does public awareness increase support for invasive species management? Promising evidence across taxa and landscape types. Biol Invasions. doi:10.1007/s10530-0171592-0

Olson LJ (2006) The economics of terrestrial invasive species: a review of the literature. Agric Resour Econ Rev 35:178-194. http://ageconsearch.umn.edu/bitstream/ 10181/1/35010178.pdf

Olson LJ, Roy S (2005) On prevention and control of an uncertain biological invasion. Rev Agric Econ 27:491-497. doi:10.1111/j.1467-9353.2005.00249.x

Panetta FD (2007) Evaluation of weed eradication programs: containment and extirpation. Divers Distrib 13:33-41. doi:10.1111/j.1472-4642.2006.00294.x

Panetta FD, Cacho OJ (2014) Designing weed containment strategies: an approach based on feasibilities of eradication and containment. Divers Distrib 20:555-566. doi:10.1111/ ddi. 12170

Pichancourt JB, Chadès I, Firn J, van Klinken RD, Martin TG (2012) Simple rules to contain an invasive species with a complex life-cycle and high dispersal capacity. J Appl Ecol 49:52-62. doi:10.1111/j.1365-2664.2011.02093.x

Picker MD, de Villiers AL (1989) The distribution and conservation status of Xenopus gilli (Anura: Pipidae). Biol Conserv 49:169-183

Pluess T, Cannon R, Jarošík V, Pergl J, Pyšek P, Bacher S (2012) When are eradication campaigns successful? A test of common assumptions. Biol Invasions 14:1365-1378. doi:10.1007/s10530-011-0160-2

Pyšek P, Hulme PE (2005) Spatio-temporal dynamics of plant invasions: Linking pattern to process 1. Biol Invasions 12:302-315. doi:10.2980/i1195-6860-12-3-302.1

Pyšek P, Richardson DM (2010) Invasive species, environmental change, and health. Annu Rev Environ Resour 35:25-55. doi:10.1146/annurev-environ-033009-095548

Ramula S, Knight TM, Burns JH, Buckley YM (2008) General guidelines for invasive plant management based on comparative demography of invasive and native plant populations. J Appl Ecol 45:1124-1133. doi:10.1111/j.13652664.2008.01502.x

Reis CS, Marchante H, Freitas H, Marchante E (2013) Public perception of invasive plant species: assessing the impact of workshop activities to promote young students' awareness. Int J Sci Educ 35:690-712

Rowe L, Ludwig D (1991) Size and timing of metamorphosis in complex life cycles: time constraints and variation. Ecology 72:413-427

Shea K, Sheppard A, Woodburn T (2006) Seasonal life-history models for the integrated management of the invasive weed nodding thistle Carduus nutans in Australia. J Appl Ecol 43:517-526. doi:10.1111/j.1365-2664.2006.01160.x

Silvertown J, Harvey M, Greenwood R, Dodd M, Rosewell J, Rebelo $\mathrm{T}$ (2015) Crowdsourcing the identification of organisms: a case-study of iSpot. ZooKeys 480:125-146

Simberloff D (2003) Eradication-preventing invasions at the outset. Weed Sci 51:247-253. doi:10.1614/00431745(2003)051[0247:EPIATO]2.0.CO;2

Simberloff D, Gibbons L (2004) Now you see them, now you don't!-Population crashes of established introduced species. Biol Invasions 6:161-172. doi:10.1023/B:BINV. 0000022133.49752 .46

Simberloff D, Martin JL, Genovesi P, Maris V, Wardle DA, Aronson J, Vilà M (2013) Impacts of biological invasions: what's what and the way forward. Trends Ecol Evol 28:58-66. doi:10.1016/j.tree.2012.07.013

Smith MA, Green DM (2005) Dispersal and the metapopulation in amphibian and paradigm ecology are all amphibian conservation: populations metapopulations? Ecography 28:110-128. doi:10.1111/j.0906-7590.2005.04042.x

Smith MA, Green DM (2006) Sex, isolation and fidelity: unbiased long-distance dispersal in a terrestrial amphibian. Ecography 29:649-658. doi:10.1111/j.2006.0906-7590. 04584.x

Steel J, Weiss J, Morfe T (2014) To weed or not to weed? The application of an agent-based model to determine the costs and benefits of different management strategies. Plant Prot Q 29:101-110

Tingley R, Ward-Fear G, Schwarzkopf L, Greenlees MJ, Phillips BL, Brown G, Clulow S, Webb J, Capon R, Strive T (2017) New weapons in the toad toolkit: a review of methods to control and mitigate the biodiversity impacts of invasive cane toads (Rhinella Marina). Q Rev Biol 92:123-149. doi:10.1086/692167

Tittensor DP, Walpole M, Hill SLL, Boyce DG, Britten GL, Burgess ND, Ye Y (2014) A mid-term analysis of progress toward international biodiversity targets. Science 346(6206):241-244. doi:10.1126/science.1257484

Van Sittert L, Measey GJ (2016) Historical perspectives on global exports and research of African clawed frogs (Xenopus laevis). Trans R Soc S Afr 71:157-166

Van Wilgen BW, Scott DF (2001) Managing fires on the Cape Peninsula, South Africa: dealing with the inevitable. J Mediterr Ecol 2:197-208

Van Wilgen BW, Davies SJ, Richardson DM (2014) Invasion science for society: a decade of contributions from the centre for invasion biology. S Afr J Sci 110:1-12. doi:10. 1590/sajs.2014/a0074

Verbrugge LNH, Van Den Born RJG, Lenders HJR (2013) Exploring public perception of non-native species from a visions of nature perspective. Environ Manag 52:1562-1573. doi:10.1007/s00267-013-0170-1

Vidal-García M, Keogh JS (2015) Convergent evolution across the Australian continent: ecotype diversification drives morphological convergence in two distantly related clades of Australian frogs. J Evol Biol 28:2136-2151. doi:10. 1111/jeb. 12746

Vilà M, Basnou C, Pyšek P, Josefsson M, Genovesi P, Gollash S et al (2009) How well do we understand the impacts of alien species on ecosystem services? A pan-European, cross-taxa assessment. Front Ecol Environ 8:135-144. doi:10.1890/080083

Vimercati G (2017) Exploring the invasion of the guttural toad Sclerophrys gutturalis in Cape Town through a multidisciplinary approach. Ph.D. Dissertation, Stellenbosch University

Vimercati G, Hui C, Davies SJ, Measey GJ (2017) Integrating age structured and landscape resistance models to disentangle invasion dynamics of a pond-breeding anuran. Ecol Modell 356:104-116. doi:10.1016/j.ecolmodel.2017.03.017 
Vonesh JR, De la Cruz O (2002) Complex life-cycles and density dependence: assessing the contribution of egg mortality to amphibian declines. Oecol 133:325-333. doi:10.1007/s00442-002-1039-9

Vos CC, ter Braak CJF, Nieuwenhuizen W (2000) Incidence function modelling and conservation of the tree frog Hyla arborea in the Netherlands. Ecol Bull 48:165-180

Warren CR (2007) Perspectives on the 'alien' versus 'native' species debate: a critique of concepts, language and practice. Prog Hum Geogr 31:427-446. doi:10.1177/ 0309132507079499

Werner EE, Gilliam JF (1984) The ontogenetic niche and species interactions in size-structured populations. Annu Rev Ecol Syst 15:393-425
With KA (2004) Assessing the risk of invasive spread in fragmented landscapes. Risk Anal 24:803-815. doi:10.1111/j. 0272-4332.2004.00480.x

Withers P, Louw G, Nicolson S (1982) Water loss, oxygen consumption and colour change in 'waterproof' reed frogs (Hyperolius). S Afr J Sci 78:30-32

Wood KA, Stillman RA, Goss-Custard JD (2015) Co-creation of individual-based models by practitioners and modellers to inform environmental decision-making. J Appl Ecol 52:810-815. doi:10.1111/1365-2664.12419 